\title{
Application of GIS and RS in real time crop monitoring and yield forecasting: a case study of cotton fields in low and high productive farmlands
}

\author{
Zokhid Mamatkulov ${ }^{1, *}$, Eshkobil Safarov ${ }^{2}$, Rustam Oymatov ${ }^{1}$, Ilhom Abdurahmanov ${ }^{1}$ \\ and Maksud Rajapbaev ${ }^{1}$ \\ ${ }^{1}$ Tashkent Institute of Irrigation and Agricultural Mechanization Engineers (TIIAME), Koriy Niyaziy \\ str., 39, 100000, Tashkent, Uzbekistan \\ ${ }^{2}$ National University of Uzbekistan named after Mirzo Ulugbek (NUUz), University str., 4, 100174, \\ Tashkent, Uzbekistan
}

\begin{abstract}
Badland reclamation and low productive farmlands always have been one of the most detrimental effects on the national economy, typically in agricultural sector of Uzbekistan. Nonetheless, such kind of lands has been used extensively for major crops like cotton and winter wheat. However, it is difficult to assessing real productivity of them. Advanced technologies as GIS and RS are vital tool for geospatially analysing and making decisions on this type of fields. This research was carried out for real-time crop monitoring and yield forecasting in case of low productive $(3.5 \mathrm{ha})$ and high productive $(8.3 \mathrm{ha})$ cotton areas of Jarkurgan district (Surkhandarya region, Uzbekistan) based on geospatial analyses of multi-temporal satellite images, condition of groundwater, soil salinity, and ground truth data. For monitoring vegetation phenology of cotton and forecasting its harvest, False Colour, NDVI (Normalized Difference Vegetation Index) and SI (Salinity Index) analyses of areas were carried out by using 6 temporal windows of multi-temporal Sentinel 2 from April through August 2019. Besides, groundwater condition data which was obtained from observation wells these located in massives consists of both cotton fields was analysed by IDW (Inverse Distance Weighting) interpolation algorithm method to determine groundwater's effect to vegetation development and yield.
\end{abstract}

Keywords: GIS, remote sensing, crop monitoring, yield forecasting, NDVI, soil index, Sentinel 2.

\section{Introduction}

Crop development monitoring and crop production estimate data is very important for all country in case of decision making on the food supply of the day-by-day growing population. Traditionally, crop yields forecasting throughout the growing season include

* Corresponding author: zohid3095@gmail.com 
models that assimilate climate, soils and other ancillary data as response functions to describe development, photosynthesis, evapotranspiration and yield for a specific crop based on strong physiological and physical concepts, these models are poor predictors when spatial variability in soils, stresses or management practices are present [1].

However, remote sensing of crop canopies has been promoted as a potentially valuable tool for agricultural monitoring because of its temporal coverage and capability of obtaining images in many spectral wavelengths [2]. All major crop models including wheat, cotton, rice, maize etc., were calibrated for yield forecasting during initial to peak growing season and estimated near harvest time [3]. As well the quality and condition of irrigated lands are the main criteria affecting expected yields in the agricultural industry [4]. About $45 \%$ of the total irrigated agricultural lands of Uzbekistan are saline in various levels [5] and in fact, this indicator has a very high negative impact on the agricultural sector of the country.

Assessment of the quality of irrigated lands and monitoring of crop development on low-yield lands are counted as a crucial issue [4]. Geo-Information Systems (GIS) and Remote Sensing (RS) technologies can be useful tools for addressing such complex issues in the agricultural sector. The main reason for this is the advances techniques like GIS and Remote Sensing can greatly contribute to managing timely, accurate, cost-efficient and repetitive information about agriculture [6]. For instance, by applying GIS and RS technologies can be of great use for monitoring the development process of cotton, identifying affected areas, determining soil quality condition, yield forecasting, visualizing real topography of crop fields and other spatial analyses in modern agriculture [7].

The scientists [8-10, 22] have revealed major application of remote sensing in agriculture including estimation of crop yield and vegetation vigour, assessment of water demand and development of vegetation, crop mapping, monitoring of land cover/use changes as well as in precision agriculture and irrigation management (Fig. 1).
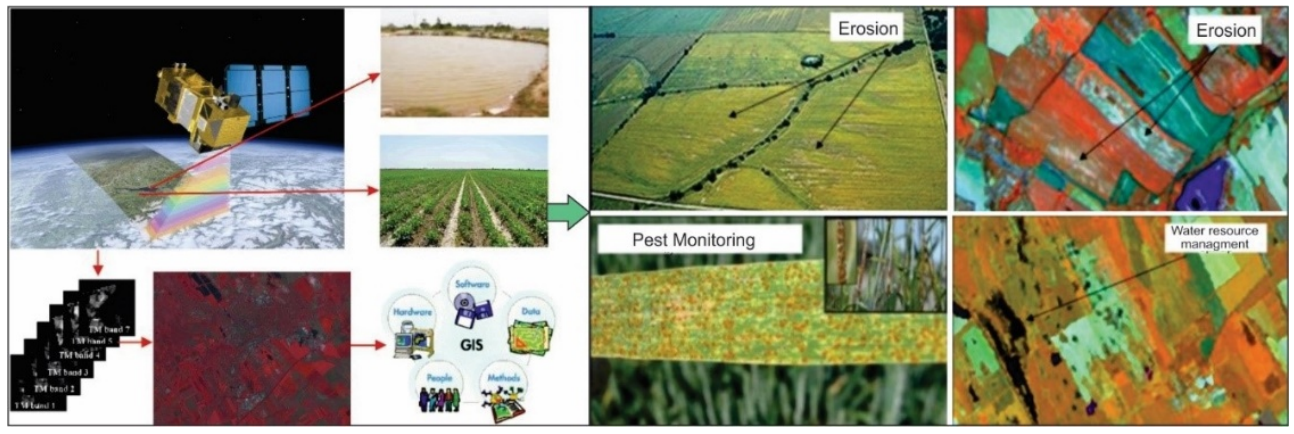

Fig. 1. Application of RS and GIS in agriculture (https://regi.tankonyvtar.hu/hu/tartalom/tamop425/0027 FHT7/ch01507.html)

These technologies also have the great potential to make rapid decisions on complex issues and positions [6]. Remote sensing gives easy access to get important expensive information about large agricultural fields. With a change of type and status of vegetation, spectral reflectance of vegetation will change.

This research is conducted on monitoring development process of cotton and predicting its harvest by using GIS and RS. Producing cotton plays an important role in the economy of Uzbekistan with widely contribution in gross domestic product (GDP), national exports and rural employment. The total cotton area covers about $40 \%$ of entire irrigated land in the country [11]. Predicting harvest earlier, helps to planning economical activities earlier. In this term particular RS methods favour to getting very important but cheap data. Many researchers as [12-14] have got positive result on cotton yield forecasting and monitoring cotton development by GIS and RS with particular approaches. Most of them used NDVI 
based on different resolution of satellite images in their research. In this research was performed based on multi data approach method in terms of monitoring cotton development and forecasting yield.

\section{Study area and methodology}

\subsection{Study area}

For this research, we selected two types: high-yielding (8.3 ha) and low-yielding (3.5 ha) cotton fields located in the Jarkurgan district of Surkhandarya region, Southern part of Uzbekistan (Fig. 2).

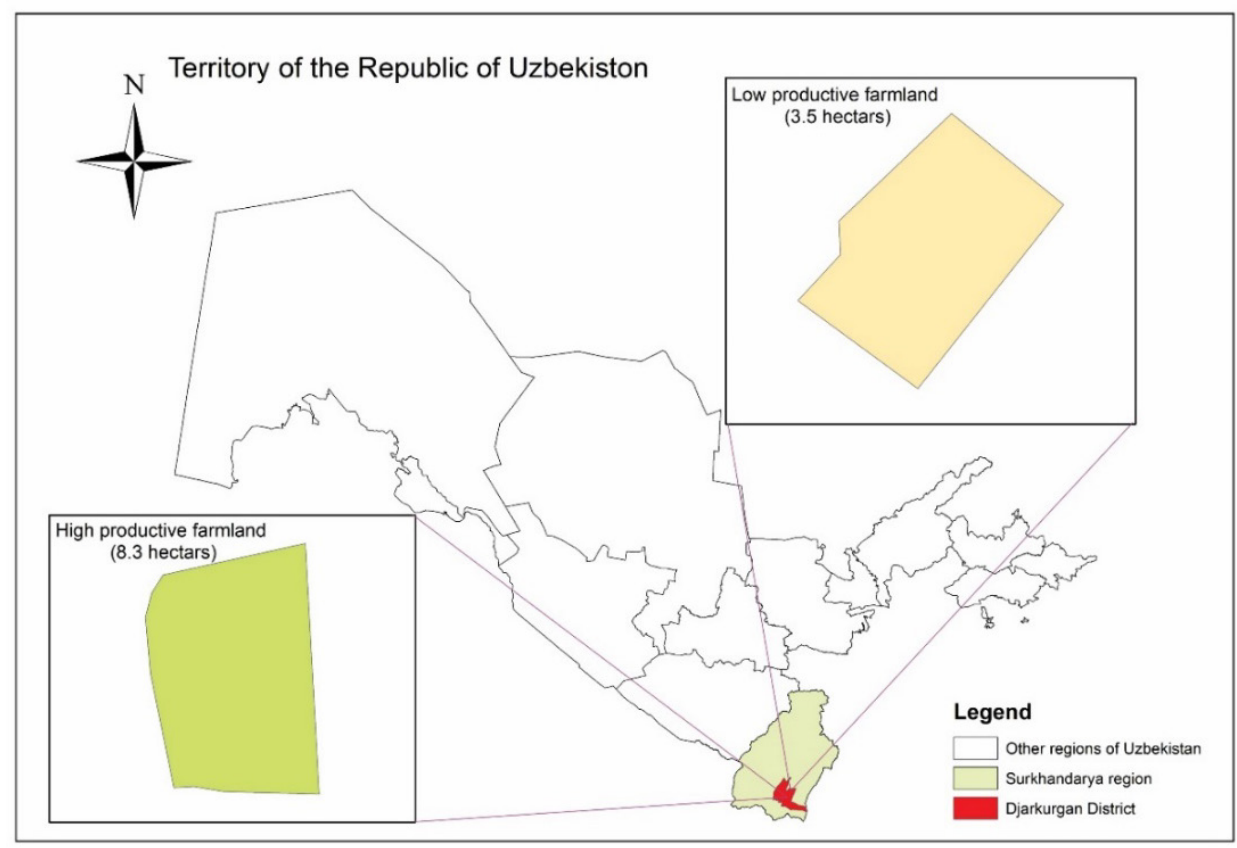

Fig.2. Locations of research areas

The overall area of the Jarkurgan district of the Surkhandarya region is 81423.0 hectares, 58878 hectares of the total area are agricultural land types and 19474.9 hectares of agricultural land types were which the irrigated agricultural lands on January 1, 2019 [15]. Especially gardening, fruits and vegetables, melons, root-fruit crops, cotton and wheat crops are considered leading main technical crops for on irrigated lands [16]. In 2019, the total irrigated agricultural land area was allocated for the cultivation of 7065 hectares of cotton and 8180 hectares of wheat, while productivity was planned to reach 23000 and 22100 tons, respectively [17]. Since the district is located in the arid region, mainly early ripening and medium-ripening varieties of cotton are grown, such as Bukhara-102, Namangan-77, Sultan, Beshkahramon and Jarkurgan. The average growth period of these cotton varieties changes between 100 and 125 days. As for the wheat varieties, which are resistant to heat and drought varieties as Yaksart, Hazrati Bashir, Babur, Asr as well as in the regions with good water supply, Grom, Krasnodar-99 and Tanya varieties are planted [18]. 
In the territory of the district, several different types of soils are distributed, depending on the natural geographic conditions and the influence of anthropogenic factors, as well as alluvial - prolyuvial, delyuvial - prolyuvial and according to alluvial deposits of the Amudarya, soil types: irrigated grey clay, brown, brown-meadow, desert - meadow, meadow-desert and desert sandy soils are distributed.

Research conducted 8.3 hectares of the cotton field with high productivity, where the mechanical content of soils, light and medium, as well as medium and none- saline soils, are widely spread. The middle level of groundwater is up to 2-3 meters. At the same time, in the area with a low fertility 3.5 hectare of the cotton field, light coarse and fine-grained, sandy soils with a low, medium, partially strongly saline and non-saline soils are common. Groundwater levels range from an average of 1.5-2.5 meters [18].

In 2013, as a result of the research carried out by the State Research Institute of Soil Science and Agro-chemistry of the State Committee of "Yergeodezkadastr", 1:10000 scaled map was created on the topic of assessing the quality of irrigated lands by the bonitet levels (from 0 to 100) of the soil of per unit fields. According to the map, bonitet levels of low and high productive areas, 38 and 69 respectively.

\subsection{Methodology}

To monitor the real-time crop development processes in research fields, 6 temporal windows of Sentinel 2 satellite images obtained on April 10, May 5, June 24, July 9, July 29 and August 23 of the year 2019 which consist of the planting of seeds until the maximum development period of the cotton. The main superiority aspects of Sentinel 2 having ability to deliver updated images of the area every 5 days interval with medium 10 meter resolution of bands: blue (2), green (3), red (4) and near-infrared (8) (Fig.s 3A, 3B and $3 \mathrm{C}$ ). With the help of combinations of bands, false colour composition is defined as the use of near-infrared, red and green bands to form map with a 3-band image instead of red, green and blue bands. False colour composition helped to monitor the growth of cotton in per field unit. Along with this, green indicators were identified through analyses of NDVI (Normalized Difference Vegetation Index) in both research cotton areas (Fig.s 3A, 3B and $3 \mathrm{C})$.

The NDVI is a widely used remote sensing indicator for crop growth monitoring, farmland management and crop production prediction [19]. For NDVI analyse, fourth (red, R) and eighth (near-infrared, NIR) bands of Sentinel 2 were used and calculated as:

$$
N D V I=(N I R-R) /(N I R+R)
$$

Crop growth monitoring and yield forecasting programs typically use the NDVI as a crucial indicator of the crop condition.

Indices of NDVI changes between -1.0 and 1.0. It means, if vegetation development well accrued in the field, most of the pixel values of the image indicate 1.0 or near to 1.0. 


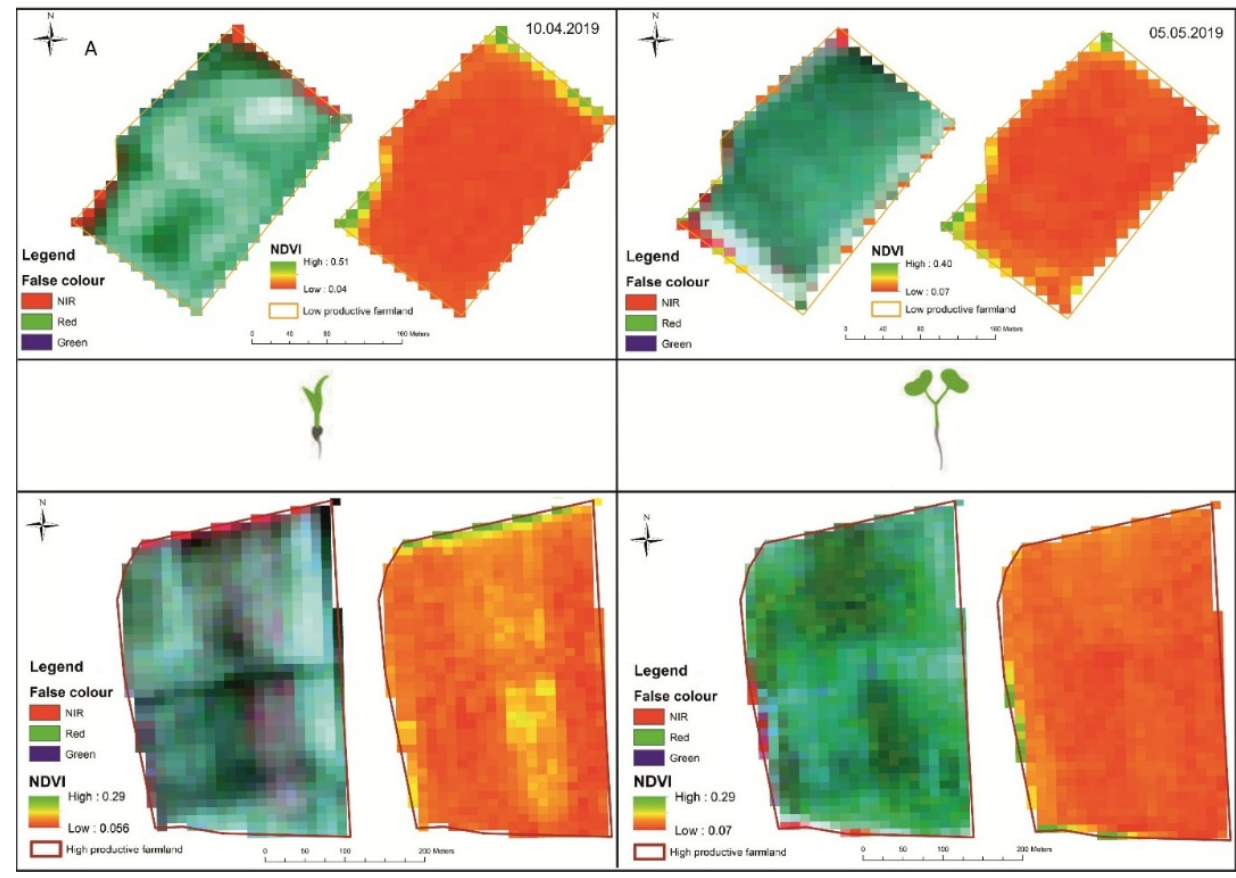

Fig. 3A. False colour composition and NDVI analyses of cotton fields with crop phenology on April 10 and May 5, 2019

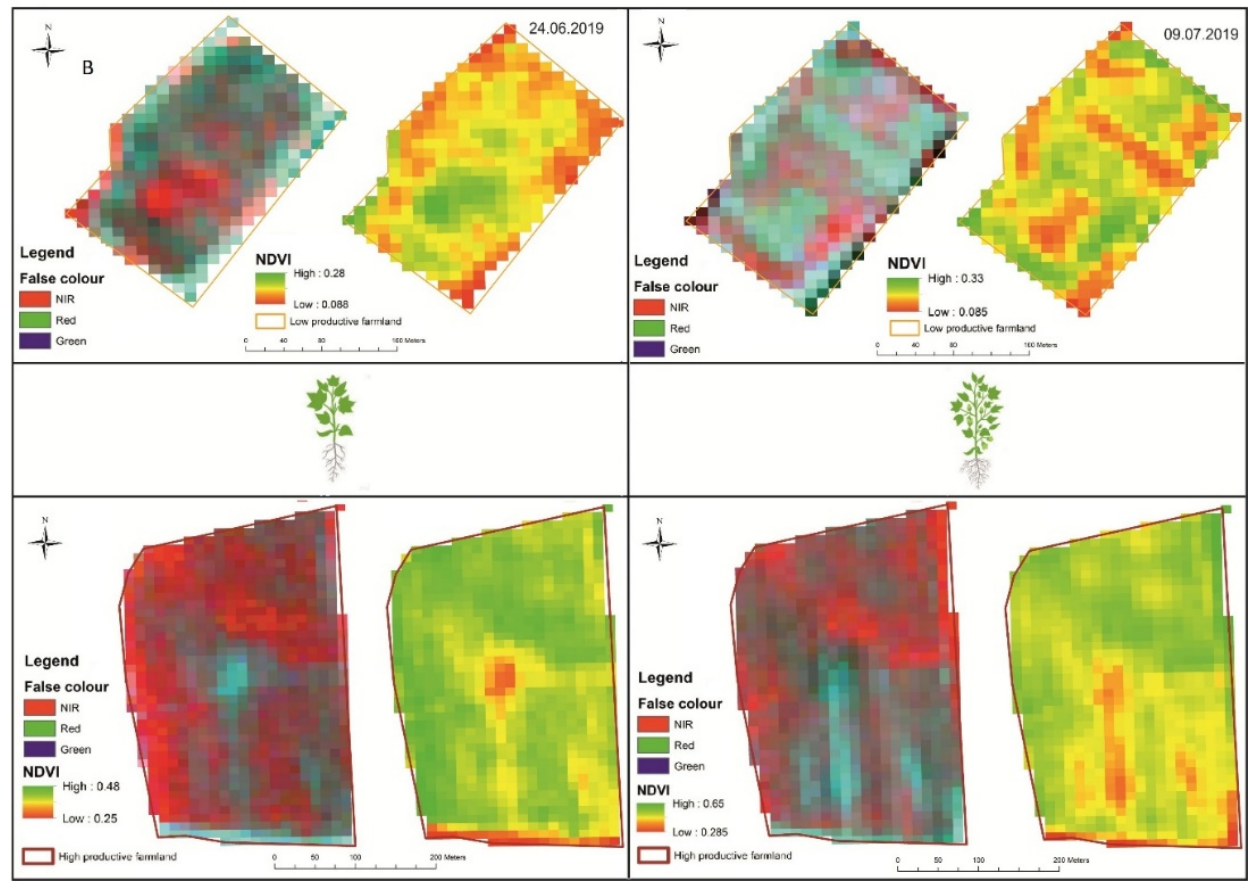

Fig. 3B. False colour composition and NDVI analyses of cotton fields with crop phenology on June24 and July 9, 2019 


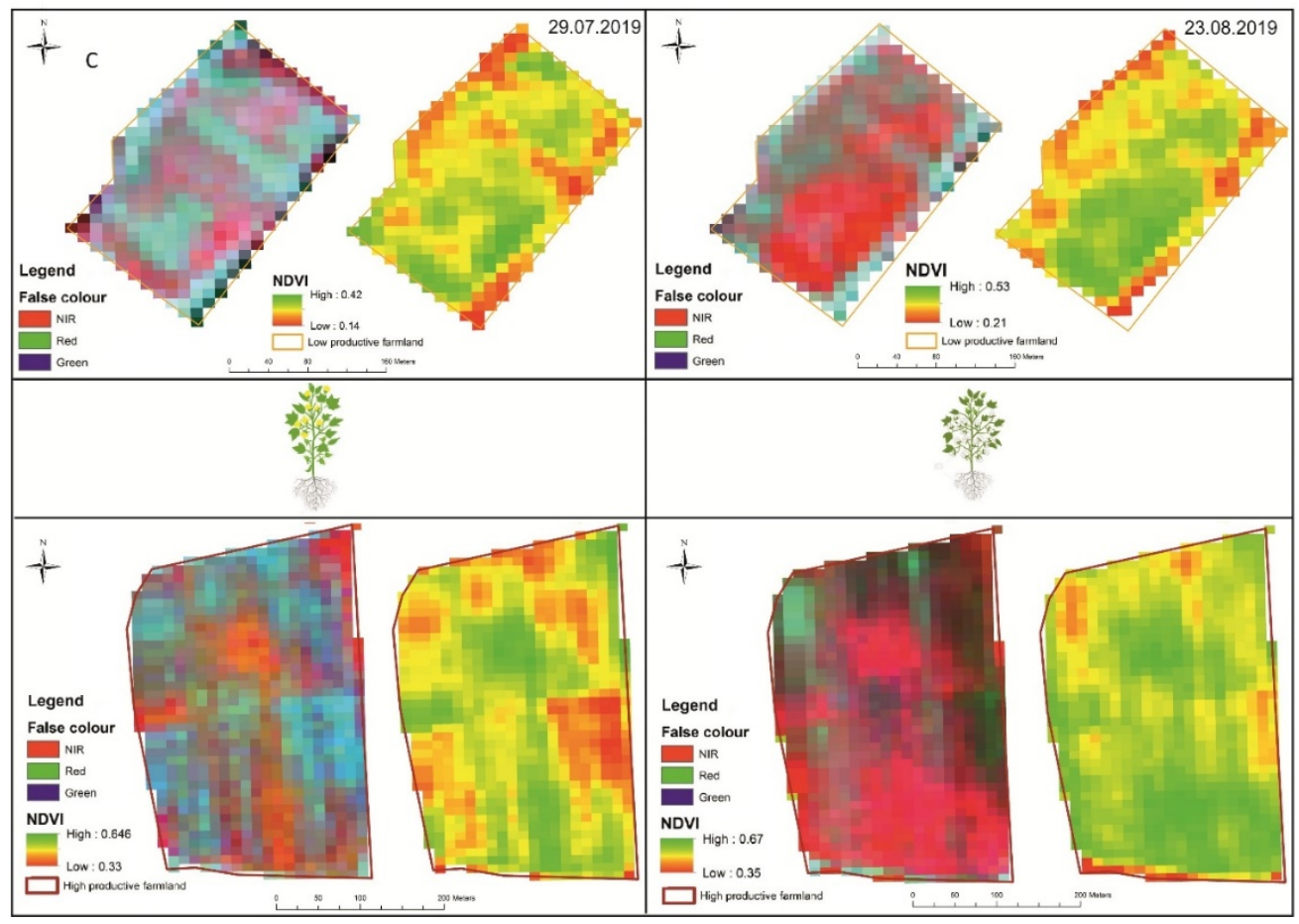

Fig. 3C. False colour composition and NDVI analyses of cotton fields with crop phenology on July 29 and August 23, 2019

The main factors affecting the deterioration of the productivity state of agricultural lands and normal development of the crop groundwater level and mineralization [20]. Therefore, data obtained from existing 9 observation wells in N.Baymurodov massive where high fertility cotton field is located and 11 observation wells in the Mirishkor massive where cotton field with low productivity is located were analysed by the IDW (Inverse Distance weighing) interpolation algorithm during the period of the high irrigation regime, July 2019 (Fig. 4).

IDW basically depends on two assumptions: (1) the unknown value of a point is influenced more by nearby control points than by those farther away, and (2) the degree of influence (weight) of points on each other is directly proportional to the inverse of the distance between the points raised to a power6and can berepresented by the following equation [21]:

$$
Z=\frac{\Sigma_{i=1}^{n} w_{i} Z_{i}}{\Sigma_{i=1}^{n} w_{i}}
$$

where, $\mathrm{Z}$ is the interpolated value for a point with an unknown observed value, wi the weighting function that determines the relative importance of each individual control point $\mathrm{Zi}$ in the interpolation procedure, $\mathrm{Zi}$ the observed value at control point $\mathrm{i}(\mathrm{i}=1, \ldots, \mathrm{n})$, which is in the closest neighborhood of the interpolated point, and $n$ the total number of such points.

The key indicator contributing to the deterioration of soil reclamation and reduced productivity is soil salinity. Remote sensing and GIS integrated approaches have been applied by numerous research methods in attempts to analyses model soil salinity in an effectively efficient way. In case of analyses, SI (Salinity Index) was carried out in order to determine the degree of salinity of soil in a cotton field with low fertility ( 3.5 ha) by remote 
sensing (Fig. 4). For determining the coverage of salinity of the soil, chosen image which was taken before planting cotton in the field (in April 2019). Otherwise, vegetation may restrict for obtaining reliable result.

Generally, there are 14 most used calculation of spectral indices of soil salinity. In this research, we used the method to calculate as:

$$
S I=(R \times N I R) / G
$$

where, G (Green)-second, R (Red) - fourth and NIR (Near infrared) eighth bands of Sentinel 2 images.

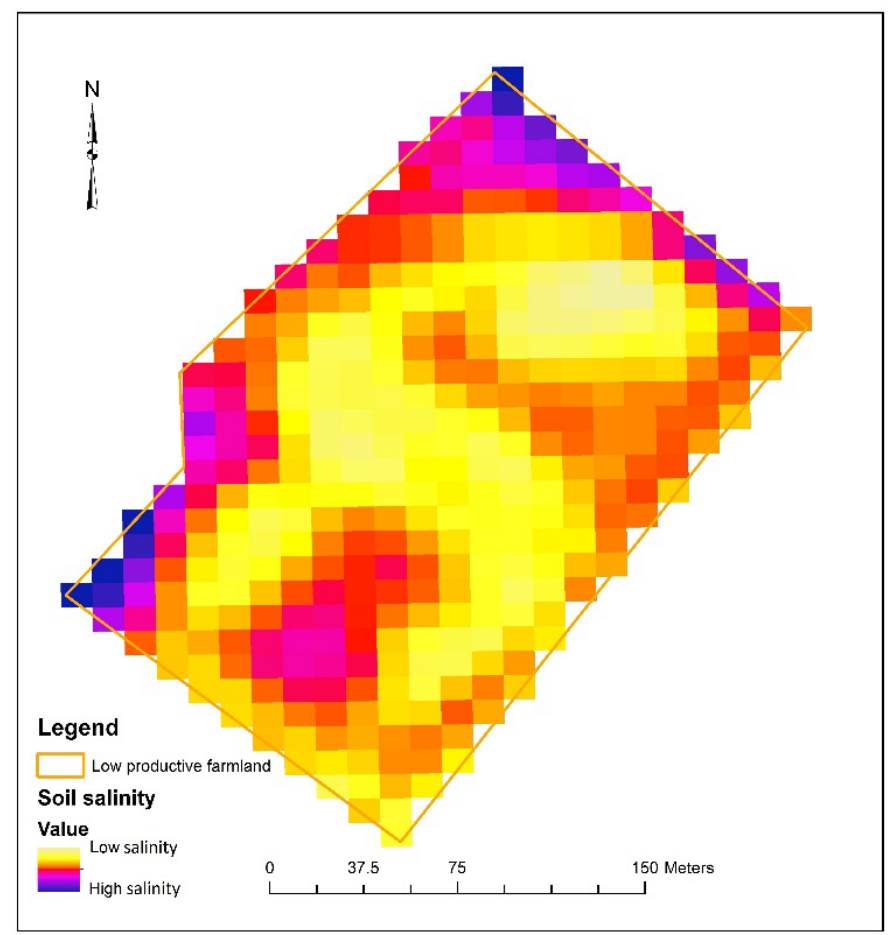

Fig. 4. Salinity index map of low productive farmland

In order to forecasting yield for both fields, a time period with the highest NDVI indicator in the cotton field with low productivity during the observation, 23.08.2019 was selected. Ground truth data were obtained from the field and linear correlation was analysed in order to compare the reliability of the results obtained and how close they are to the reality (Fig. 5).

\section{Results and discussion}

In terms of analysing crop monitoring, research reveals that (Figures 3A, 3B, 3C), the vegetation process was not smoothly developed in a 3.5 ha cotton field with low productivity. According to False Colour and NDVI, the normal development of the crop was occurred only in the central parts of the field, far from the centre of the field, it can be seen a significant sparsely and not well development of vegetation. The maximum value of NDVI analysis of images taken in July-August when the time of highest vegetation period, the low productive cotton field was considered as 0.53 while this indicator showed 0.67 for 
the highly productive cotton field (Figure 3C). As the main factors influencing to the development of the plant, it can be possible to include poor agricultural activities, inadequate irrigation, low consumption of mineral fertilizers, etc. Also, the level of groundwater and mineralization (salinity) in the area have a great influence on the land reclamation state as well as on the normal growth of the plant. If the groundwater level and mineralization are high, the crop might be damaged [4]. From the models developed through the IDW interpolation algorithm (Figures 3A and 3B), it can be seen that in the research conducted low productive cotton field is located in 1.57-1.80 meters of groundwater levels and 1.40-1.60 $\mathrm{g} / \mathrm{l}$ of groundwater mineralization (salinity) part of massive. Taking into account the fact that the root of the cotton is the arrowroot and penetrates to a depth of 1.5-2.0 meters, the groundwater level is higher than the accepted norm and it was assumed that GW has a significant negative effect to cotton development. The cotton field with high fertility is located in an area with groundwater levels at a depth of 3-5 meters, which does not show a negative result in the development of the crop. Results showed that mineralization of groundwater is normal for both cotton fields.

However, when determining the degree of soil salinity with SI analysis, (Figure 5) showed that the presence of salinity in the field with low fertility of almost half of the field $(43 \%)$ was saline.

Using the NDVI, GPS points obtained on the way to the locations and the comments given to their condition, harvest forecasting map of low productive farmland developed was developed (Figure 6). The minimum value of NDVI under the condition of 23.08.2019 of the low yielded research field was 0.21 while the highest value was 0.53 . It was concluded that when comparing the results obtained by in situ data and performing a correlation analysis, the yield could be available if the minimum value of NDVI indicates higher than 0.35 in cotton fields. When the NDVI indicators which higher than 0.35 extracted, only $2.27(64 \%)$ ha of the overall area with well-developed and yielded cotton. The main reason that the field with high productive farmland was not conducted, that in the case of 23.08.2019 the minimum value of NDVI from this field was higher than 0.35 (Figure 3C).

The yield of the major crops by soil bonitet level is calculated as follows:

$$
Y=A \times B \times C \text {, sentner }
$$

where, $\mathrm{A}$ is the vegetation-covered area of the field (2.27 ha a part from 3.5 ha of the low productive area covered with vegetation), $\mathrm{B}$ is soil quality, which ranges from 0 to 100 . In our case, soil quality is equal to 38 point. $\mathrm{C}=0.4$, which is a special coefficient for cotton yield calculation.

If we calculate the yield of low productive farmland field in future based on the above formula, harvest forecasted as:

$$
Y=2.27 \times 0.4 \times 38=34.5 \text { sentner }=3.45 \text { tons }
$$

In fact, for this area expected harvest was 5.3 tons before planting. In this case, the damage that may occur near to 1.8 tons. The formula which was used for harvest calculation applied for high productive farmland ( 8.3 hectares) and expected harvest was equal to 23.2 tons. However, real harvest was 22.5 tons and accuracy is $96 \%$. For low productive farmland, yield forecasting accuracy is some lower $(85 \%)$ than other. The real harvest was 2.93 tons. 


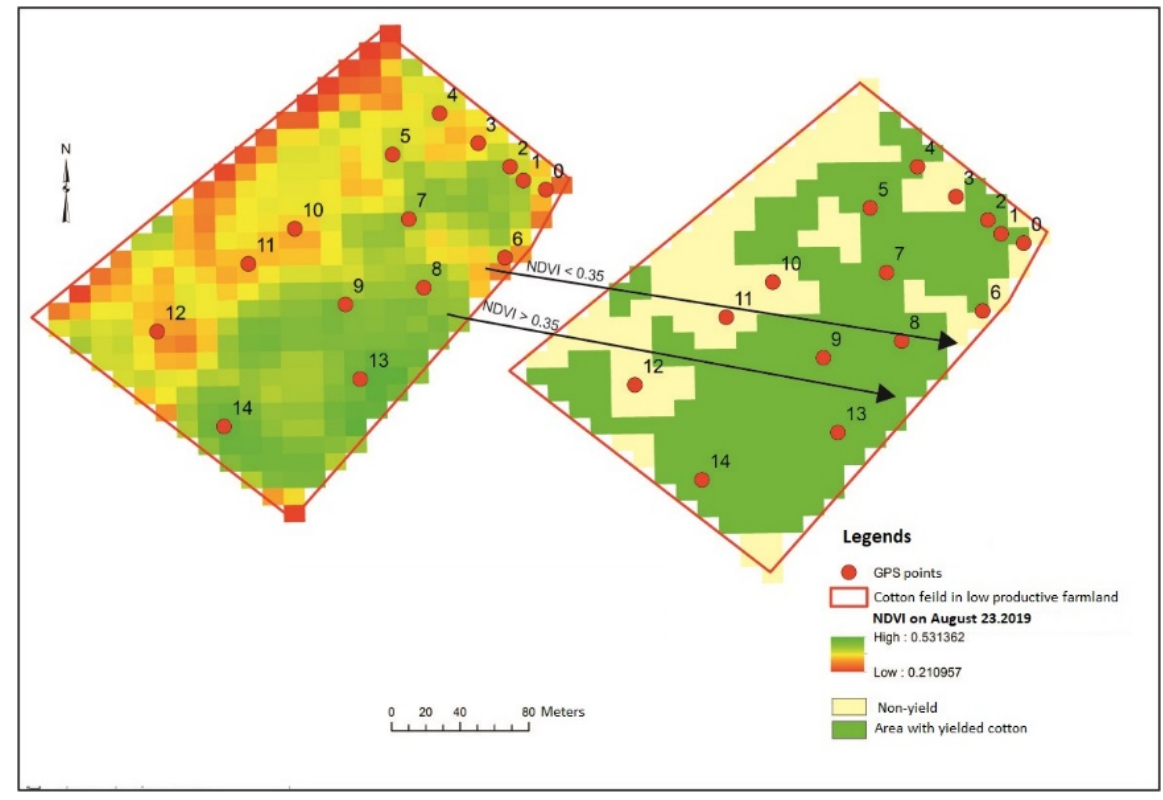

Fig. 5. Extracting yielded cotton area from NDVI

\section{Conclusion and recommendation}

In the case of making a decision through remote sensing and GIS-based Multiple Data Approach (MDA) may give a higher accuracy for conducted research. Remote sensing and GIS-based agriculture monitoring is an important component of the food security information system which provides reliable and timely crop area estimates and crop production forecasts at national, regional and global scales. Formulated indices (NDVI, SI) from spatial-temporal Sentinel 2 images as well as other ancillary environmental data like groundwater condition, soil quality and expert knowledge may give more reliable model on crop development and predicting yield. For utilizing these kinds of advanced technologies, require a high level of ability to use software devices and computer technologies as well as the high level of theoretical and practical expert knowledge in the application sphere.

\section{References}

1. C. L. Wiegand. The value of direct observations of crop canopies for indicating growing conditions and yield. The 18th International Symposium on Remote Sensing of Environment, 18, 1551 (Paris, 1984).

2. N. A. Quarmby, M. Milnes, T.L. Hindle and Silleos. The use of multi-temporal NDVI measurements from AVHRR data for crop yield estimation and prediction. Inter. J. Remote Sens., 14, 199 (1993)

3. I. Ahmad, D. A. Awan, M. Bhatti, I. H. Akhtar, M. Ibrahim. Satellite Remote Sensing and GIS based Crop Forecasting System in Pakistan. Crop monitoring for improvement food security, 95 (FAO, 2014)

4. T. Sh. Beisenboyev, N.F. Bespalov, Salinization dynamics of irrigated soils and cotton productivity. Tashkent (1993)

5. Annual report of Ministry of Water Resources of the Republic of Uzbekistan (2018) 
6. P. Kingra, D. Majumder. Application of Remote Sensing and GIS in Agriculture and Natural Resource Management Under Changing Climatic Conditions. Agri. Research J., 53(3), 295 (2016)

7. Z. J. Mamatkulov, E.Yu. Safarov, R.K. Oymatov, I.I. Abdurahmanov. Application of GIS and Remote Sensing in crop monitoring and yield forecasting in case of lowyielded farmlands. J. Problems Architecture. Const., Samarkand, Spatial Volume, 130 (2019)

8. C. Atzberger. Advances in remote sensing of agriculture: context description, existing operational monitoring systems and major information needs. J. Remote Sens, 5, 949 (2013)

9. T. Bernardes, M. A. Meriera, M. Adami, A. Giarolle and B. F. Rudorff. Monitoring biennial bearing effect on coffee yield using MODIS remote sensing imagery. Journal of Remote Sens, 4, 2492 (2012)

10. T. Sakamoto, M. Yokozawa, H. Toritani, M. Shibayama, N. Ishitsuka. A crop phenology detection method using time series MODIS data. Journal of Remote Sens Environ, 96, 366 (2005)

11. S. Macdonald, United States Department of Agriculture. Retrieved from www.usda.gov/oce/forum (2018)

12. Y. Huang, S. Thomson, Remote Sensing for Cotton Farming (2015)

13. N. Ramarao, Conformity Analysis of Cotton Crop using Remote Sensing and GIS, (Geospatial World, 2009)

14. D. Atakhanov, Cotton yield forecasting in Tashkent province by using Remote Sensing techniques.https://www.wur.nl/en/activity/Cotton-yield-forecasting-in-Tashkentprovince-by-using-Remote-Sensing-techniques.htm (2013)

15. Land Fund of the Republic of Uzbekistan (2019)

16. Report of the scientific-research institute of Soil Science and agro-chemistry on the creating soil maps of irrigated land areas and soil evaluation of massives of Jarkurgan District of the Surkhandarya region (Tashkent, 2013).

17. Annual report of the Ministry of Agriculture of the Republic of Uzbekistan (2018)

18. Reports of scientists of the centre of scientific -industrial agriculture of Uzbekistan, (2015)

19. L. Congcong, L. Hongjun, L. Jiazhen, L. Yuping, L. Chunqiang, K. Manevski, Y. Shen. Using NDVI percentiles to monitor real-time crop growth. Journal of Computer and Electronics Agri., 162, 357 (2019)

20. K. Isabaev, M. Khamidov, D. Alieva, Crop irrigation and productivity. (Tashkent, 1991)

21. P. M. Bartier, C.P Keller. Multivariate interpolation to incorporate thematic surface data using inverse distance weighting (IDW). Journal of Computers \& Geosciences, 22, 795 (1996)

22. M. Verőné Wojtaszek, Földhasználati tervezés és monitoring (precíziós mezőgazdaság). Land use planning and monitoring (precision agriculture) https://regi.tankonyvtar.hu/hu/tartalom/tamop425/0027_FHT7/ch01s07.html (2010) 